\title{
DRUG UTILIZATION STUDY OF FLUOROQUINOLONE ANTIBIOTICS IN A UNIVERSITY TEACHING HOSPITAL
}

\author{
Juno J. Joel*, Muneerudeen J, Shastry C.S \\ Department of Pharmacy Practice, NGSM Institute of Pharmaceutical Sciences, Mangalore, Karnataka, India \\ *Corresponding authorse-mail: junojoel@nitte.edu.in, Phone: +919480470727
}

\begin{abstract}
It is well known that antibiotics are prescribed abundantly in hospitalized patients especially in critical care settings. The antibiotic usage will also vary depends on the type of therapy, physicians perceptions and availability of the drug. Our aim was to study the drug utilization pattern of Fluoroquinolone (FQs) antibiotics in medicine and surgery wards of a tertiary care hospital. A total of 100 patients who received FQs were enrolled in the study and the FQ utilization was measured in terms of DDD/100 bed days. Mean \pm SD number of drugs prescribed and length of hospital stay were $8.23 \pm 3.33$ and $11.54 \pm 7.57$ respectively. Ciprofloxacin was the most commonly prescribed drug. Overall Fluoroquinolone utilization was found to be 33.55 DDD/100 bed-days.
\end{abstract}

Key words: Defined daily dose, drug utilization, fluoroquinolones.

\section{INTRODUCTION}

Antibiotics are the most frequently prescribed drugs among hospitalized patients especially in intensive care and surgical department. Encouraging appropriate antibiotic prescriptions in health institutions is an important element in quality of care, infection control and cost containment ${ }^{1}$. The development of bacterial resistance to antibiotics has become a major problem throughout the world ${ }^{2}$. Antimicrobial resistance results in increased morbidity, mortality, and rising cost of health care ${ }^{3,4}$. Monitoring of antimicrobial use and knowledge of prescription habits are some of the strategies recommended to contain resistance to antimicrobials in hospitalized patients. Our study focused in analyzing drug utilization pattern of Fluoroquinolones in the Medicine and Surgery wards of the hospital.

\section{MATERIALS AND METHODS:}

This study was carried out in the medicine and surgery wards of a 1000 bedded private tertiary care teaching hospital. The study was conducted for a period of seven months. Permission was obtained from Institutional Ethics
Committee before starting the study. The data were collected from patients of all age groups from either sex, who got admitted to the medicine and surgery wards of the hospital.

A suitable data collection form was designed to collect and document the data. Data collection form includes demographic details of patient; drug therapy details (name of drug, dosage form, frequency, route of administration, duration of treatment) and length of stay. Data were collected from the patient's file on a daily basis.

Comparison of prescribed daily doses of FQs with defined daily doses was carried out using ATC/DDD Index 2013. The DDD/100 bed-days of all the FQs prescribed in the Medicine and Surgery ward was calculated. The DDD/100 bed-days of the individual FQs were added together to get the total FQ consumption.

The use of individual Fluoroquinolones and of the group as a whole was measured using the defined daily dose (DDD)/100 bed-days using the following formula ${ }^{5}$ :

$\mathrm{DDD} / 100$ bed-days $=\quad$ No. of units administered in the study period $(\mathrm{mg}) \times 100$ DDD (mg) x No. of days in study period $x$ No. of beds $x$ bed occupancy

Data of all the patients were analyzed with the help of Microsoft Access Data Sheet version 2010.

\section{RESULTS:}

We have enrolled 100 patients in the study who, were prescribed with FQs during the study period. It includes 67 males and 33 female patients. The majority of the patients $(22 \%)$ were in the age group of 15-25 years followed by $(19 \%)$ in the age group 56-65 years. The age wise distribution of the patients is presented in (Table 1).
Table 1: Age Distribution of Study Population

\begin{tabular}{|c|c|}
\hline Age (years) & No. of patients $(\mathbf{n = 1 0 0})$ \\
\hline $15-25$ & 22 \\
\hline $26-35$ & 10 \\
\hline $36-45$ & 14 \\
\hline $46-55$ & 16 \\
\hline $56-65$ & 19 \\
\hline $66-75$ & 14 \\
\hline $76-85$ & 5 \\
\hline
\end{tabular}


A total of 823 drugs were prescribed. The mean \pm SD of drugs prescribed was $8.23 \pm 3.33$. For an individual patient, a particular drug prescribed by different brand names and administered by different routes was taken as a single drug for the purpose of calculation. The maximum number of patients $(67 \%)$ was admitted in the Medicine wards and rest (33\%) was admitted in the Surgery wards. The number of drugs prescribed per patient is presented in (Table 2).

Table 2: Number of Drugs Prescribed During the Period of Hospitalization

\begin{tabular}{|c|c|c|}
\hline S. N. & $\begin{array}{c}\text { Number of drugs in the } \\
\text { prescription }\end{array}$ & $\begin{array}{c}\text { Number of patients } \\
\text { received }\end{array}$ \\
\hline 1 & $1-4$ & 8 \\
\hline 2 & $5-8$ & 51 \\
\hline 3 & $9-12$ & 30 \\
\hline 4 & $13-16$ & 10 \\
\hline 5 & $>16$ & 1 \\
\hline
\end{tabular}

Twenty patients were admitted for a period of 1 to 5 days, 37 patients for 6 to 10 days, 21 patients for 11 to 15 days, 10 patients for 16 to 20 days, 5 patients for 21 to 25 days and 7 patients for greater than 25 days. Mean \pm SD duration of hospital stay was $11.54 \pm 7.57$ days.

Out of 100 patients 87 received FQs as monotherapy and 13 patients received multiple drug therapy. The agents prescribed as monotherapy in large numbers were Ciprofloxacin (54.02\%) followed by Levofloxacin (31.03\%). The commonly prescribed multiple drug therapy was Ciprofloxacin + Levofloxacin $(53.84 \%)$. The details on the utilization of FQs as monotherapy and multiple drug therapy are presented in (Table $3 \& 4$ ).

Table 3: Fluoroquinolones Prescribed as Monotherapy in Study Population

\begin{tabular}{|c|c|c|}
\hline Fluoroquinolones & $\begin{array}{c}\text { No. of patients } \\
(\mathbf{n = 8 7})\end{array}$ & $\begin{array}{c}\text { Percentage } \\
(\mathbf{\%})\end{array}$ \\
\hline Ciprofloxacin & 40 & 45.98 \\
\hline Levofloxacin & 27 & 31.03 \\
\hline Ofloxacin & 12 & 13.79 \\
\hline Norfloxacin & 8 & 9.2 \\
\hline
\end{tabular}

Table 4: Fluoroquinolones Prescribed as Multiple Drug Therapy in Study Population

\begin{tabular}{|c|c|c|}
\hline Fluoroquinolones & $\begin{array}{c}\text { No. of patients } \\
(\mathbf{n = 1 3})\end{array}$ & $\begin{array}{c}\text { Percentage } \\
(\mathbf{\%})\end{array}$ \\
\hline $\begin{array}{c}\text { Ciprofloxacin }+ \\
\text { Levofloxacin }\end{array}$ & 7 & 53.84 \\
\hline $\begin{array}{c}\text { Ciprofloxacin }+ \\
\text { Norfloxacin }\end{array}$ & 5 & 38.47 \\
\hline $\begin{array}{c}\text { Ciprofloxacin }+ \\
\text { Gemifloxacin }\end{array}$ & 1 & 7.69 \\
\hline
\end{tabular}

FQ usage in both the wards during the study period was calculated in terms DDD/100 bed-days. In our study DDD/100 bed-days for FQs was found to be 33.55. Ciprofloxacin was the most frequently prescribed FQ (15.72 DDD/100 bed-days), followed by Levofloxacin (12.54 DDD/100 bed-days). The ATC code and the DDD/100 bed-days of the prescribed FQs are presented in (Table 5).

Table 5: ATC Code and DDD/100 Bed-Days of Fluoroquinolones Prescribed

\begin{tabular}{|l|c|c|}
\hline \multicolumn{1}{|c|}{ Drug Name } & ATC Code & DDD/100 beddays \\
\hline Ciprofloxacin Oral & J01MA 02 & 13.19 \\
\hline Ciprofloxacin Parentral & J01MA 02 & 2.53 \\
\hline Levofloxacin Oral & J01MA 12 & 9.426 \\
\hline Levofloxacin Parentral & J01MA 12 & 3.11 \\
\hline Norfloxacin Oral & J01MA 06 & 2.92 \\
\hline Ofloxacin Oral & J01MA 01 & 2.37 \\
\hline Total & & 33.55 \\
\hline
\end{tabular}

The Prescribed Daily Doses of FQs were compared with the Defined Daily Doses indexed in the WHO Collaborating Centre for Drug Statistics Methodology (ATC/DDD Index 2013). We have observed the Prescribed Daily Doses, which are same for all the class of FQs except Ciprofloxacin. The Prescribed Daily Doses of Ciprofloxacin for parenteral route was $0.4 \mathrm{G}$ whereas the Defined Daily Dose Ciprofloxacin for parenteral route was found to be $0.5 \mathrm{G}$ according to WHO Collaborating Centre for Drug Statistics Methodology (ATC/DDD Index 2013). This was mainly because, the Inj. Ciprofloxacin $100 \mathrm{ml}$ which contains Ciprofloxacin $200 \mathrm{mg}$ which was prescribed twice daily. The comparison detail of Prescribed Daily Dose with Defined Daily Dose is presented in (Table 6).

Table 6: Comparison of Prescribed Daily Doses with Defined Daily Doses

\begin{tabular}{|l|l|l|l|l|l|l|}
\hline ATC Code & Fluroquinolone & PDD & Units & Rout of administration & DDD & Units \\
\hline J01MA01 & Ofloxacin & 0.4 & $\mathrm{G}$ & Parentral & 0.4 & $\mathrm{G}$ \\
& & 0.4 & $\mathrm{G}$ & Oral & 0.4 & $\mathrm{G}$ \\
\hline J01MA02 & Ciprofloxacin & 0.4 & $\mathrm{G}$ & Parentral & 0.5 & $\mathrm{G}$ \\
& & 1 & $\mathrm{G}$ & Oral & 1 & $\mathrm{G}$ \\
\hline J01MA06 & Norfloxacin & 0.8 & $\mathrm{G}$ & Oral & 0.8 & $\mathrm{G}$ \\
\hline J01MA12 & Levofloxacin & 0.5 & $\mathrm{G}$ & Parentral & 0.5 & $\mathrm{G}$ \\
& & 0.5 & $\mathrm{G}$ & Oral & 0.5 & $\mathrm{G}$ \\
\hline
\end{tabular}




\section{DISCUSSION:}

All the FQs were prescribed by their brand names. It was also seen that the less costly standard brands were used. The maximum number of patients $(67 \%)$ who received FQs was admitted in the Medicine wards, the rest (33\%) were admitted in the Surgery wards.

In our study Ciprofloxacin was the most frequently prescribed FQ followed by Levofloxacin. This was in contrast to the study conducted in the United States where it was observed that there is an increase in the usage of Levofloxacin $^{6}$. In our study DDD/100 bed-days for FQs was found to be 33.55 . The $\mathrm{DDD} / 100$ bed-days of Ciprofloxacin and Levofloxacin was found to be 15.72 and 12.54 respectively. This indicates the highest utilization of Ciprofloxacin followed by Levofloxacin within the Medicine and Surgery wards of the hospital. A study conducted Gordana $\mathrm{P}$ et al, concluded that the overall FQ utilization was found to be $29.81 \mathrm{DDD} / 100$ bed-days $^{7}$. In another study it was found that parenteral ciprofloxacin was prescribed (82.643 DDD/100 BD) and parenteral Levofloxacin was prescribed (3.188 DDD/100 BD) . In our study we found that parenteral Ciprofloxacin was $(2.53$ DDD/100 BD) whereas parenteral Levofloxacin prescribed was (3.11 DDD/100 BD).

During the study period one patient of age 15 years was found to be prescribed with FQs. A research on safety and efficacy of Ciprofloxacin in children in developing countries was reviewed by Green $\mathrm{S}$ et al, and they concluded that Ciprofloxacin was safe and efficacious ${ }^{9}$. However, it is better to be cautious while prescribing FQs in children due to conflicting reports. In our study location, there are no set of criteria for prescribing FQs in

\section{REFERENCES}

1. Krivoy N, El-ahal WA, Bar-lavie Y, Haddad S. Antibiotic prescription and cost patterns in a general intensive care unit. Pharmacy Practice., 2007; 5(2):67-73.

2. Raveh D, Muallem-zilcha E, Greenberg A, Wiener-well, Y. Schlesinger, Yinnon AM. Prospective drug utilization evaluation of three broad-spectrum antimicrobials: cefepime, piperacillin-tazobactam and meropenem. Q J Med., 2006; 99:397-406

3. Struelens MJ. The epidemiology of antimicrobial resistance in hospital acquired infections: problems and possible solutions. BMJ 1998;317:652-4.

4. Gold HS, Moellering RC. Antimicrobial-drug resistance. N Engl J Med., 1996;335:1445-53.

5. Xavier D. Pharmacoepidemiology and drug utilization studies In: Continuingmedical education Workshop in Pharmacology children and the decision to include the drug in the prescription is left to the individual physician.

Among the study population, we noticed 35 patients, who received FQs empirically. The most common clinical conditions, that are treated empirically with FQs were acute gastroenteritis [15 (42.86\%)], lower respiratory tract infections [06 (17.14\%)] etc.

In an American study report, FQs were found to be the commonly prescribed drug for UTIs, sinusitis, skin infections and urinary tract infections ${ }^{6}$. In a previous study it was observed that Ciprofloxacin was mainly used to treat conditions like UTIs, chest infections, bacterial gastroenteritis, and bacteraemia ${ }^{10}$.

\section{CONCLUSION:}

The most common FQs prescribed were found to be Ciprofloxacin followed by Levofloxacin. We have observed the utilization of quinolone was higher than those reported in previous studies whereas the parenteral FQ utilization was less than those reported in previous studies. This is a good sign as injections are expensive, need of trained manpower and may also carry the risk of transmission of infections. We suggest that there is also a need of guidelines and policies regarding the use of FQs. This will effectively minimize the errors on the use of antibiotics which may promote rational drug use and better care on patients.

\section{ACKNOWLEDGMENTS:}

The authors thank Dr. Rama Prakasha, Assistant Professor, Dept of Medicine, KSHEMA and all other health care providers in the Dept of Surgery for their continuous support and guidance during the study period.

9th-12th February 1999.Department of Pharmacology, St. John's Medical College, Bangalore, India.

6. Linder JA, Huang ES, Steinman MA, Gonzales R, Stafford RS. Fluoroquinolone prescribing in the United States: 1995 to 2002. Am J Med., 2005; 118:259-68.

7. Gordana P, Zorica J, Karin V. Application of the atc/ddd methodology to compare antibiotic utilization in two university hospital surgical departments. Journal of Medicine and Biology., 2005;12(3):174-8.

8. Al-Tawfiq JA. Changes in the pattern of hospital intravenous antimicrobial use in Saudi Arabia, 2006-2008. Ann Saudi Med., 2012;32(5):517-20.

9. Green S, Tillotson G. Use of ciprofloxacin in developing countries. Pediatr Infect Dis J., 1997; 16:150-9.

10. Feucht CL, Rice LB. An interventional program to improve antibiotic use. Ann Pharmacother., 2003;(5):646-51. 